\title{
PELANGGARAN STRUKTUR PERCAKAPAN DALAM ACARA MATA NAJWA DI TRANS7
}

\author{
Nina Puspita Dewi Setianingrum \\ (Pendidikan Bahasa dan Sastra Indonesia, Fakultas Keguruan dan Ilmu Pendidikan, \\ Universitas PGRI Adi Buana Surabaya) \\ ninadewi0796@gmail.com
}

\section{Rahayu Pujiastuti}

(Pendidikan Bahasa dan Sastra Indonesia, Fakultas Keguruan dan Ilmu Pendidikan, Universitas PGRI Adi Buana Surabaya) rahayu_pujiastuti@unipasby.ac.id

\begin{abstract}
Najwa's eye is a show on Trans7 aired every Wednesday at 20:00 pm. Every week the topic of discussion in the Najwa Eye event varies. One of the topics of discussion taken this week on the 100 Days of the Anis-Password, because the news about the performance of Anis-Sandi is warmly discussed among the public. There are many violations encountered regarding the conversational structure contained in the Najwa Eye event. Based on this research, this study aims to find out two things, namely (1) violation of the structure of the conversation and (2) the purpose of the violation is done.Researchers use a qualitative approach. This research data in the form of conversation that contains violation of conversation structure in Mata Najwa event. Sources of data in this research in the form of document data written Mata Najwa with 100 Days Anis-Sandi topic. Technique of collecting data is done by documentation. Data analysis techniques used are identification, data grouping, interpretation, and draw conclusions.Based on the result of the research, it can be concluded that (1) Violation of conversation structure in the Najwa Eye event there are two violations, namely the turn-taking and the adjacency pairs. (2) The purpose of violation of the structure of the conversation in the Najwa Eye event, ie to explain in detail, to get the attention of the speech partner, to maintain the continuity of the speech so as not to stop, and to bring up a new, different but still in one discussion.
\end{abstract}

Keywords: Violation of Conversational Structure and Purpose of Violation.

\section{PENDAHULUAN}

Bahasa merupakan sistem lambang bunyi yang digunakan oleh anggota suatu masyarakat untuk berkomunikasi, bekerja sama, dan mengidentifikasikan diri (Kridalaksana dalam Chaer, 2012:32). Penggunaan bahasa seseorang sangat memengaruhi proses berlangsungnya interaksi. Interaksi merupakan sarana setiap orang untuk menyampaikan gagasan, maksud, dan informasi yang dapat memengaruhi satu sama lain. Dalam menyampaikan gagasan, maksud, maupun informasi yang dapat memberikan pengaruh terhadap satu sama lain, setiap orang tentu mengeluarkan sebuah ujaran sebagai alat penyampaian yang utama saat berinteraksi.

Bahasa dapat ditinjau dari segi internal dan eksternal. Dalam segi internal meliputi fonologi, morfologi, sintaksis, semantik. Dalam segi eksternal meliputi pragmatik.

Pragmatik merupakan studi tentang makna yang disampaikan oleh penutur dan ditafsirkan oleh 
pendengar (Yule, 2006:3). Pragmatik mengkaji hubungan bahasa dengan konteks dan hubungan pemakaian bahasa dengan pemakai atau penuturnya. Dalam tindak operasionalnya, kajian pragmatik berupaya menjelaskan penggunaan bahasa dari penuturnya. Kajian dalam pragmatik meliputi deiksis, implikatur, praanggapan, tindak-tutur, dan sruktur percakapan.

\section{Struktur}

percakapan

merupakan komponen yang terdapat pada sebuah percakapan antarpenutur. Jenis percakapanya mungkin juga berbeda menurut konteks interaksi yang berbeda, akan tetapi struktur pembicaraannya berpola dasar dari "Saya bicara - Anda bicara - Saya bicara - Anda bicara" berasal dari jenis interaksi mendasar yang kali pertama kita peroleh dan yang paling sering kita gunakan (Yule, 2006:121122). Dalam struktur percakapan terdapat tiga model, yaitu model giliran berbicara (turn-taking), pasangan ajasensi (adjacency pairs), dan percakapan terencana (Overall Organization).

Hal yang menarik untuk dianalisis pelanggaran struktur percakapannya yaitu dalam acara "Mata Najwa" di Trans7. Mata Najwa tayang setiap hari rabu pukul 20.00 WIB. Setiap minggu topik pembahasan dalam acara Mata Najwa berbeda-beda, pada bulan Januari terdapat tiga topik pembahasan. Salah satu topik pembahasan yang diambil minggu ini mengenai 100 Hari AnisSandi, sebab pemberitaan mengenai kinerja Anis-Sandi sedang hangat dibicarakan dikalangan masyarakat. Berikut salah satukutipan pelanggaran percakapan yang terdapat dalam acara Mata Najwa.

GB Anis : "Inilah kenyataan dilapangan, justru ketika seperti itu ditempatkan sebagai

feedback bahwa kita mencoba menyelesaikan masalah

kemudian ada muncul reaksi, dan karena kita datangnya pagi. Kebanyakan dari pembeli maupun penjual belum muncul disitu. Jadi sebagian dan saya ingin sampaikan

ketika..."

Najwa : "Sudah agak ramai begitu kita datang mas, ketika datang sudah mulai buka buka"

GB Anis : "Ooo itu belum apaapa, Mbak Nana berapa kali ke Tanah Abang. Kalau

datang kesana siang wuih lebih ramai lagi"

Berdasarkan percakapan yang bercetak miring Bapak Anis menanggapi protes pedagang tanah abang, ketika sidak ke lokasi 2 hari yang lalu dan di dampingi oleh Najwa. Ketika bapak Anis sedang menjelaskan tiba-tiba Najwa memotong pembicaraan begitu saja. Hal ini ditujukan untuk mengklarifikasi perbedaan pandangan suasana di pasar tersebut.

Berdasarkan hal tersebut, penelitian pelanggaran struktur percakapan dalam acara Mata Najwa mempunyai dua pertanyaan penelitian, yaitu bagaimana pelanggaran struktur percakapan dalam acara Mata Najwa di Trans7 dan bagaimana tujuan pelanggaran struktur percakapan dalam acara Mata Najwa di Trans7, penelitian ini bertujuan untuk mengetahui pelanggaran struktur percakapan dalam acara Mata Najwa dan tujuan melakukan pelanggaran dalam acara Mata Najwa.

Manfaat dalam penelitian ini untuk menambah wawasan pengetahuan yang berhubungan dengan pragmatik khususnya pengetahuan tentang strukur 
percakapan yang sengaja di langgar untuk tujuan tertentu, memahami analisis struktur percakapan, hasil penelitian ini dapat dijadikan sebagai sumber ide bagi peneliti lain untuk penelitian sejenis, dan hasil penelitian ini dapat dijadikan sebagai sumber ide untuk bahan ajar disekolah.

\section{METODE PENELITIAN}

Pendekatan yang digunakan dalam penelitian ini adalah pendekatan kualitatif. Penelitian ini meggunakan metode deskriptif, yaitu metode yang digunakan untuk mengambarkan atau menganalisis suatu hasil penelitian tetapi tidak digunakan untuk membuat kesimpulan yag lebih luas. Data dari penelitian inni berupa percakapan yang mengandung pelanggaran struktur percakapan dalam acara Mata Najwa yang meliputi giliran berbicara (turntaking), pasangan ajasensi (adjacency pairs), dan percakapan terencana (Overall Organization).

Sumber data penelitian ini adalah sumber data dokumen tertulis berupa video Mata Najwa dengan topik 100 Hari Anis-Sandi, meliputi (a) Tujuh sekmen dengan topik pembicaraan yang berbeda, (b) Percakapan anatara Najwa-Anis, (c) Percakapan antara Najwa-Sandi, (d) Percakapan antara Najwa-AnisPKL, (e) Percakapan antara NajwaRustika Herlambang.

Adapun langkah-langkah yang dilakukan dalam pengumpulan data, antara lain (a) Mengunduh video, (b) Mengamati dan mendengaran percakapan yang terdapat dalam video, (c) Mentranskipsi percakapan sesuai dengan data yang terdapat dalam video, (d) Menyimpan data yang telah ditranskipsi. Adapun langkah-langkah analisis data dalam penelitian ini adalah (a) identifikasi, (b) pengelompokan data, (c) interpretasi,

(d) menarik simpulan.

\section{HASIL PENELITIAN}

Hasil penelitian dan pembahasan mengenai pelanggaran struktur percakapan meliputi dua hal, yaitu pelanggaran giliran berbicara (turn-taking) dan pelanggaran pasangan ajasensi. Serta tujuan pelanggaran struktur percakapan.

\section{Pelanggaran Giliran Berbicara (turn-taking)}

\section{a. Interupsi}

Pada saat overlap yang menunjukkan persaingan dapat ditandai dengan adanya interupsi dan penutur yang memperoleh hak berbicara sedang berbicara, hal ini dapat ditandai dengan suara yang lantang. Ketika terjadi interupsi maka seorang penutur telah melanggar peraturan, karena penutur tersebut belum mendapatkan hak berbicara. Berikut adalah contoh pelanggaran interupsi dalam acara Mata Najwa di Trans7.

(PSP.GB.In.1)

Pedagang 2 : "Tidak jarang pelanggan saya

malah ada orang ibu-ibu hamil, merekasusah jadi aksesnya gitu"

GB Anies : "Jadi dengan adanya kemungkinan..."

Walikota : "Permisi pak

Gubernur, jadi

kalau ada yang belanja bawa

disitu barangnya bisa masuk"

Berdasarkan percakapan yang bercetak miring, termasuk ke dalam pelanggaran giliran berbicara yaitu interupsi. Hal ini terjadi karena pedagang 2 bercerita kepada Bapak Anis mengeluhkan permasalahan yang terjadi di Pasar Tanah Abang. Ketika penjelasan beliau belum usai, bapak 
walikota memotong pembicaraan dengan memberi Interupsi dengan kata permisi.

(PSP.GB.In.4)

Najwa : "Mas mengosongkan trotoar itu tadi itu tadi

trotoar di jual beli satu

setengah sampai dua

setengah juta mas Anies"

GB Anies : "Saya teruskan dulu, jadi ini kemaren, iya betul.

Jadi kalau kita

membandingkan,

bandingkan antara sekarang

dan dulu bukan bagaimana

sekarang kenapa kalau dulu

sama sekali..."

Berdasarkan percakapan yang

bercetak miring, terdapat pelanggaran yaitu interupsi. Bapak Anies kemudian menyanggah pertanyaan dari Najwa dengan memberikan interupsi terlebih dahulu, hal ini dimaksudkan agar Najwa memberi kesempatan kepada bapak Anies untuk menjelaskan.

\section{b. Overlap}

Overlap terjadi pada kedua penutur yang mencoba berbicara pada saat bersamaan. Secara khusus overlap terjadi ketika kedua penutur berusaha untuk berinisiatif bicara. Menurut aturan, seorang penutur akan berhenti dan membiarkan penutur lainnya menggunakan hak bicaranya. Berikut adalah contoh pelanggaran overlap dalam acara Mata Najwa di Trans7. (PSP.GB.Ov.3)

Pedagang 1 : "Tuh, disitu tu saya bertahan berjualan

untuk anak bu"

(menunjukkan lokasi berjualan)

Najwa : "Ehh nggak boleh

katanya ibu berjualan

disitu"

Pedagang 1 : "Lah makanya kalau

ada tenda saya kebawah bu, karena gak

dapat tenda"

Najwa : "Oke"

Berdasarkan percakapan yang bercetak miring, terdapat pelanggaran overlap. Hal ini terjadi sebab Pedagang 1 menunjukkan lokasi berjualan yang kebetulan lokasi Pedagang 1 adala lokasi yang dilarang untuk berjualan. Pedagang1 mengakui kalau salah, tapi ia membela diri karena belum mendapatkan tenda, dari pembelaan tersebut terdapat tumpang tindih percakapan.

(PSP.GB.Ov.4)

Pedagang 2 : "Hee e gini kita akses jalan masuk pertokoan ditutup pak, sama pedagang kaki lima, jadi kita benar-benar tidak dikasih akses untuk masuk" GB Anies : "Ooo lobanglobangnya harus ditambahin ya"

Pedagang 2 : "Iya ditutup sama sekali"

GB Anies : "Nanti biar ditambahin aja, di bukain"

Walikota : "Eee ditutup"

Pedagang 2 : "Nggak dikasih"

Walikota : "Nanti bisa kita cek"

Najwa : "Bapak jualannya dimana, tokonya dimana"

Pedagang 2 : "Toko disitu"

Berdasarkan percakapan yang bercetak miring, terdapat pelanggaran overlap. Hal ini terjadi sebab Pedagang 2 mengeluh akibat kebijakan baru yang diterapkan oleh Bapak Anies yang memperbolehkan berjualan dijalan, hal ini berdampak besar kepada pemilik toko yang akses jalannya terhalang oleh pedagang. Dari percakapan tersebut terdapat beberapa percakapan yang tumpang tindih.

\section{c. Memotong Pembicaraan}


Berbicara disuatu forum, baik formal maupun tidak formal pasti akan menemukan satu titik masalah yang akan diperdebatkan guna menemukan jalan keluar permasalahan tersebut. Dalam proses itu pasti kita akan menemukan pemotongan pembicaraan yang dilakukan oleh penutur kepada penutur lain, hal ini bisa diakibatkan karena ketidak setujuan oleh pihak lain. Berikut adalah contoh pelanggaran memotong pembicaraan dalam acara Mata Najwa di Trans7. (PSP.GB.Mp.1)

GB Anies : "Inilah kenyataan
dilapangan,
seperti itu
ditempatkan sebagai feedback
bahwa kita mencoba
menyelesaikan masalah
kemudian ada muncul
reaksi, dan karena kita
datangnyar pagi.

Kebanyakan dari pembeli maupun penjual belum muncul disitu. Jadi sebagian dan saya ingin

sampaikan
$\begin{aligned} & \text { Najwa } \\ & \text { begitu kita }\end{aligned}$
$\begin{aligned} & \text { ketika datang } \\ & \text { buka-buka }\end{aligned}$
datang mas,

(memotong pembicaraan)"

GB Anies : "Ooo itu belum apaapa, Mbak Nana berapa kali ke Tanah Abang.

Kalau datang kesana siang wuih lebih ramai lagi"

Berdasarkan percakapan yang bercetak miring Bapak Anis menanggapi protes pedagang tanah abang, ketika sidak ke lokasi dua hari yang lalu dan di dampingi oleh Najwa. Ketika bapak Anis sedang menjelaskan tiba-tiba Najwa memotong pembicaraan begitu saja. Hal ini ditujukan untuk mengklarifikasi perbedaan pandangan suasana di pasar tersebut.

(PSP.AP.Mp.6)

GB Anies : "Tidak tahu apa yang terjadi, saya jelaskan sedikit' Najwa : "Sudah melihat kenyataan dilapangan berarti ya"

GB Anies : "Saya jelaskan sedikit soal ini, bahkan ketika kita mau melaksanakan kita undur pelaksanaannya sampai bulan Desember. Kenapa, karena kita mau memastikan semua pihak yang terkait itu diajak bicara. Baik itu dari kepolisian, baik itu dari warga, baik itu angkot, baik itu pedagang semuanya kita ajak bicara satu-satu" Berdasarkan percakapan yang bercetak miring terdapat pelanggaran yaitu, memotong pembicaraan. Hal ini terjadi pada saat Najwa mempertanyakan masalah ketidak ikut sertaan Polda dalam pengubahan kebijakan lalu lintas diarea Jalan Jati Baru. Dalam percakapan yang bercetak miring tersebut Najwa selalu memotong pembicaraan bapak Anies.

\section{d. Hold the floor (nyerocos)}

Nyerocos dapat menyatakan suatu tindakan, keberadaan, pengalaman, atau pengertian dinamis lainnya. Nyerocos termasuk dalam ragam bahasa cakapan. Berikut adalah contoh pelanggaran memotong pembicaraan dalam acara Mata Najwa di Trans7.

(PSP.GB.Ny.1)

GB Anies : "Kemudian pasar ada juga, nah jadi kita yang mau kita lakukan adalah mengelola agar lalu lintas orang yang datang lewat stasiun tanah abang dan kegiatan perbelanjaan itu bisa dikelola dengan baik itu tujuannya" 
Najwa : "Dengan cara menutup ruas jalan didepan stasiun dan kemudian agar trotoarnya lancar dengan orang, itu salah satu.."

GB Anies : "Bukan bukan, dengan cara membuka trotoar dari PKL"

Berdasarkan percakapan yang bercetak miring, merupakan suatu pelangaran hold the floor (nyerocos). Dalam percakapan tersebut Najwa menutarakan pendapatnya tanpa diberi jeda, dan bapak Aniespun langsung menyanggah pendapat dari Najwa tanpa menunggu Najwa berhenti mengutarakan pendapatnya.

(PSP.GB.Ny.12)

Wagub Sandi : "Ya itu masukanlah

buat kita dan kalau di

ranah politik gak usah

di debatlah, kita si

fokusnya kerja aja. Kita focus

lapangan pekerjaan.

Bagaimana bagaimana oke oce itu bukan hanya sukses di pelatihan pendampingan

tapi bisa menciptakan

lapangan

pekerjaan

dimana"

Najwa : "Oke, jadi-jadi itu

dianggap jadi masukan

saja begitu ya,

masukkan saja"

Wagub Sandi : "Ya, tentunya, harus

jadi masukkan"

GB Anies : : Apa lagi Mata

Najwa Cuma ambil satu

fraksi"

Najwa : : "Yang diambil PDI

Perjuangan"

Berdasarkan percakapan yang bercetak miring, terdapat pelanggaran yaitu nyerocos. Hal ini terjadi karena terdapat percakapan pak Sandi yang belum usai lalu Najwa menanggapi pernyataan pak Sandi tersebut, tanpa menunggu pak Sandi menyelesaikan pernyataannya. Dengan begitu percakapan tersebut menjadi tumpang tindih. Dalam peristiwa ini bapak Sandi dan Najwa cenderung berbicara tanpa aturan yakni menghiraukan giliran berbicara, di tambah lagi pak Anies menyeletuk mengambil alih giliran berbicara, hal ini bisa dikatakan nyerocos.

\section{Pasangan Ajasensi}

\section{a. Mengalihkan Pembicaraan}

Dalam suatu percakapan pengalihan pembicaraan ke topik lain biasa terjadi. Hal ini bisa diakibatkan karena adanya keterkaitan antara satu masalah terhadap masalah lainnya atau satu topik terhadap topik lainnya. Berikut adalah contoh pelanggaran mengalihkan pembicaraan dalam acara Mata Najwa di Trans7.

(PSP.AP.Mp.2)

GB Anies : "Di depannya di

buka gak"

Pedagang 2 : "Ketika saya protes seringkali saya cekcok dengan pedagang,

karena mereka beranggapan mereka merasa benar mereka merasa ini adalah program dari pemerintah"

Percakapan yang bercetak miring tersebut adalah pelanggaran Ajasensi Pairs, yaitu mengalihkan pembicaraan. Seperti jawaban yang diutarakan Pedagang 2 yang meleceng dari pertanyaan, namun tetap dalam satu topik.

(PSP.AP.Mp.13)

Najwa : "Mas Anies kontrak politik itu spesifik menyebut e apakah ini yang saya dapat kalau memang salah silakan kemudian anda bantah kontrak politiknya itu perlindungan dan penataan ekonomi informal didalamnya PLK, becak, nelayan tradisional, pekerja rumah tangga, asongan, pedagang kecil, dan pasar tradisional. Jadi kalimatnya 


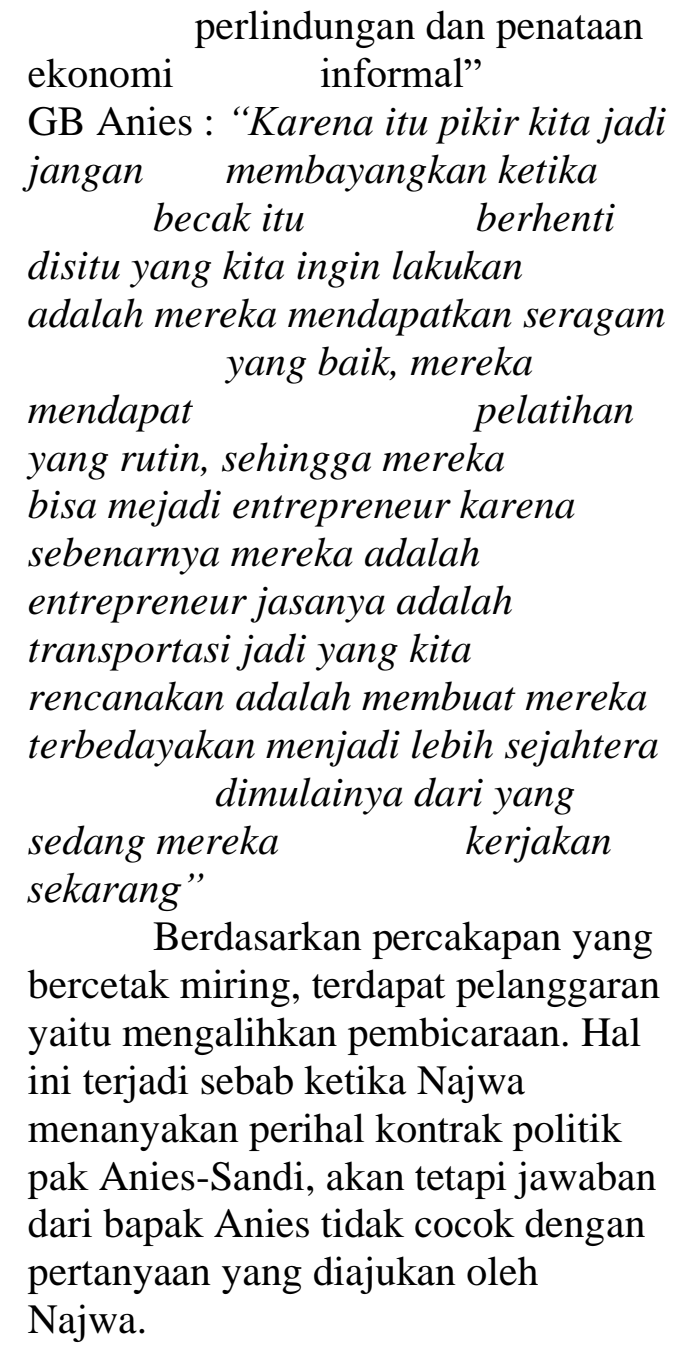

\section{Tujuan Pelanggaran Struktur Percakapan}

a. Mencuri

Mencuri merupakan cara mengambil alih giliran berbicara pada waktu pembicara terdahulu belum selesai berbicara. Pembicara pertama umumnya tidak menduga bahwa mitra tuturnya akan mengambil alih giliran berbicara pada saat ia belum menyelesaikan pembicaraannya. Berikut adalah contoh tujuan pelanggaran mencuri dalam acara Mata Najwa di Trans7.

(TPSP.M.2)

Pedagang 2 : “Tidak jarang pelanggan saya malah ada orang ibu-ibu hamil,

\begin{abstract}
mereka susah jadi aksesnya gitu"

GB Anis : "Jadi dengan adanya kemungkinan..."

Walikota : "Permisi pak

Gubernur, jadi kalau ada

yang belanja bawa disitu

barangnya bisa masuk"

Berdasarkan percakapan yang

bercetak miring, ketika bapak Anies mejelaskan permasalahan yang ada. Tiba-tiba pak walikota mencuri pembicaraan untuk mengambil alih giliran berbicara pada saat pak Anies menyelesaikan pembicaraannya. Hal ini ditujukan untuk menjelaskan jalan masuk untuk pertokoan.
\end{abstract}

\section{b. Merebut}

Merebut merupakan cara mengambil alih giliran berbicara pada saat pembicara terdahulu sedang berbicara dan masih ingin melanjutkan pembicaraanya. Alih tutur yang terjadi semacam itu pada umumnya dimaksudkan untuk memperoleh perhatian yang lebih dari mitra tuturnya. Berikut adalah contoh tujuan pelanggaran merebut dalam acara Mata Najwa di Trans7

(TPSP.Mr.1)

Najwa : "Ehh nggak boleh

katanya ibu

berjualan disitu"

Pedagang 1 : "Lah makanya kalau ada tenda saya kebawah bu, karena gak dapat tenda"

Berdasarkan percakapan yang bercetak miring, ketika Najwa sedang bertanya ke pedagang tersebut, tibatiba pedagang itu merebut pembicaraan dari Najwa untuk mengambil alih giliran berbicara hal ini ditujukan untuk mebela diri dan menceritakan keluh kesah karena tidak kebagian tenda.

(TPSP.Mr.3) 
GB Anies : "Inilah kenyataan

dilapangan, justru ketika

seperti itu ditempatkan

sebagai feedback bahwa kita

mencoba menyelesaikan masalah

kemudian ada muncul reaksi, dan

karena kita datangnya pagi.

Kebanyakan dari pembeli maupun penjual belum muncul disitu. Jadi sebagian dan saya ingin sampaikan ketika..."

Najwa : "Sudah agak ramai begitu kita datang mas, ketika datang sudah mulai buka buka (memotong pembicaraan)",

Berdasarkan percakapan yang bercetak miring Bapak Anies menanggapi protes pedagang Tanah Abang, ketika sidak ke lokasi 2 hari yang lalu dan di dampingi oleh Najwa. Ketika bapak Anis sedang menjelaskan tiba-tiba Najwa mencuri pembicaraan untuk mengambil alih giliran berbicara pada saat ia belum menyelesaikan pembicaraannya. Hal ini ditujukan untuk mengklarifikasi perbedaan pandangan suasana di pasar tersebut.

\section{c. Mengganti}

Menggati merupakan cara mengambil alih giliran berbicara dengan cara melanjutkan tuturan mitra tutur karena mitra tuturnya tidak mampu memahami tuturan. Pengambilan tuturan ini dimaksudkan untuk mempertahankan keberlangsungan tuturan agar tidak terhenti. Berikut adalah contoh tujuan pelanggaran mengganti dalam acara Mata Najwa di Trans7.

(TPSP.Mg.2)

GB Anies : "Dijalan pasar baru, yang disebut sebagai pasar baru itu sudah tidak ada jalannya lagi dipakai $100 \%$ untuk perindustrian"
Najwa : "Enggak pertanyaan saya anda ingin memakai saran dari Polda atau tidak?"

GB Anies : "Kita mengikuti semua saran"

Najwa : "Semua saran, tetapi dari Polda tidak belum tentu akan di ikuti"

Berdasarkan percakapan yang bercetak miring, Najwa berkali-kali mengganti percakapan untuk mengambil alih giliran berbicara. Pengambilan giliran ini dimaksudkan untuk memertahankan keberlangsungan tuturan dan bermasud untuk mempermudahkan kepada lawan tutur agar lebih memahami pertanyaan yang dimaksud.

\section{d. Menciptakan}

Menciptakan merupakan cara mengambil alih giliran bertutur dengan cara memunculkan tuturan baru yang berbeda tapi masih ada kaitan dengan tuturan sebelumnya. Berikut adalah contoh tujuan pelanggaran menciptakan dalam acara Mata Najwa di Trans7.

(TPSP.Mc.3)

GB Anies : "Ooo itu belum apa-apa, Mbak Nana berapa kali ke Tanah Abang. Kalau datang kesana siang wuih lebih ramai lagi"

Najwa : "Jadi artinya tiga orang yang datang itu yang protes kepada anda bukan cerminan keadaan yang sesungguhnya, nah anda mau mengatakan seperti itu"

Berdasarkan percakapan yang bercetak miring, ketika bapak Anies menyanggah pertanyyan dari Najwa. Akan tetapi Najwa berusaha menciptakan pembahasan baru, hal ini bertujuan untuk memertahankan 
giliran berbicara agar proses percakapan itu tidak cepat selesai dan mendapatkan jawaban yang pasti sekaligus tidak bertele-tele.

(TPSP.Mc.4)

Najwa : "Mas Anies apakah berarti waktu itu Polda tidak diajak

berbicara ya?"

GB Anies : "Diajak berbicara terlibat, bahkan ini.."

Najwa : "Tapi kemudian sarannya seperti ini apa yang terjadi?" GB Anies : "Tidak tahu apa yang terjadi, saya jelaskan sedikit" Najwa : "Sudah melihat kenyataan dilapangan berarti ya"

Berdasarkan percakapan yang bercetak miring Najwa berusaha menciptakan pertanyaan baru agar proses percakapan itu tidak cepat selesai, hal ini bertujuan untuk memertahankan giliran berbicara dan mendapatkan jawaban yang pasti.

\section{PEMBAHASAN}

Berdasarkan kajian yang sudah dilakukan oleh peneliti terhadap pelanggaran struktur percakapan dalam acara Mata Najwa. Pada penelitian ini ditemukan sebuah pelanggaran struktur percakapan dan tujuan terjadinya pelanggaran struktur percakapan. Dalam acara ini, peneliti menemukan dua bentuk pelanggaran strukur percakapan yaitu pelanggaran giliran berbicara dan pasangan ajasensi. Pelanggaran giliran berbicara yang terdapat dalam acara ini adalah interupsi, overlap, memotong pembicaraan, dan nyerocos. Selain itu pelanggaran pasangan ajasensi yang terdapat dalam acara ini adalah mengalihkan pembicaraan.

Selain itu dalam acara Mata Najwa terdapat tujuan melakukan pelanggaran yang dilakukan oleh penutur. Tujuan-tujuan pelanggaran tersebut untuk menjelaskan secara rinci, memperoleh perhatian dari mitra tutur, mempertahankan keberlangsungan tuturan agar tidak terhenti, dan memunculkan tuturan baru yang berbeda namun tetap dalam satu pembahasan.

\section{SIMPULAN DAN SARAN}

Berdasarkan hasil penelitian dapat disimpulkan bahwa:

1. Pelanggaran struktur percakapan dalam acara Mata Najwa terdapat dua pelangaran, yaitu pelanggaran giliran berbicara (turn-taking) yang terjadi karena interupsi, overlap, memotong pembicaran, dan hold the floor (nyerocos). Pelanggaran pasangan ajasensi (adjacency pairs) yang terjadi karena mengalihkan pembicaraan.

2. Tujuan pelanggaran struktur percakapan dalam acara Mata Najwa, yaitu untuk menjelaskan secara rinci, memperoleh perhatian dari mitra tutur, mempertahankan keberlangsungan tuturan agar tidak terhenti, dan memunculkan tuturan baru yang berbeda namun tetap dalam satu pembahasan.

Penulis ingin memberikan saran yang berhubungan dengan penelitian ini. Saran ini diharapkan menjadi sumbangsih yang bermanfaat bagi berbagai pihak, antara lain sebagai berikut.

1. Bagi Pembaca

Menambah wawasan pengetahuan tentang strukur percakapan yang sengaja dilanggar untuk tujuan tertentu.

2. Bagi Peneliti Lain

Hasil penelitian ini diharapkan dapat menjadi sumber ide untuk melakukan penelitian yang sejenis. 
DAFTAR PUSTAKA

Chaer, Abdul. 2012. Linguistik Umum. Jakarta: Rineka Cipta

Moleong, Lexy J. 2012. Metodologi Penelitian Kualitatif. Bandung: PT Remaja Rosdakarya
Yule, George. 2006. Pragmatik. (terjemahan Indah Fajar Wahyuni). Yogyakarta: Pustaka Pelajar 